\section{The Threat of Cyberattack in East Asia}

Bhatta, G. P. (2010), Does NepaliStock Market Follow Random Walk?, SEBON Journal, 4, 18-58.

Black, F., Scholes, M. (1973), The pricing options and corporate liabilities, Journal of Political Economy, 81(3), 637-654.

Cuthbertson, B. (1996), Quantitative Financial Economics, John Wiely \& Sons, New York.

G.C., Surya Bahadur (2010), Weak Form of Market Efficiency: Evidence from Nepali Stock Market, Available at http://dx.doi.org/10.2139/ ssrn. 1568694.

G.C., Surya Bahadur (2008), Volatility Analysis of Business Studies, 5(1), 76-84

Gurung, J.B. (2004), Growth and performance of securities Market in Nepal, The Journal of Nepali Business Studies, 1(1), 85-92.

Joshi, N., K.C., Fatta Bahadur (2005), The Nepali Stock Market: Efficiency and Calendar Anomalies. Nepal Rastra Bank, 17, 43-87

Kadaria, S. (2011), Market reaction to tangible and Journal, 2(1), 41-64.

Kendall, M. G. (1953),T he Analysis of Economic Time-Series, Part I. Prices, Journal of the Royal Statistical Society, 116(1), 11-34.

Lo, A.W., Mackinlay, A.C. (1988), Stock Market Prices Do Not Follow Random Walks: Evidence from a Simple Specification Test, Review of Financial Studies, 1(1), 41-66. Nepali Stock market, The journal of Nepali intangible information: A case of Nepal, Banking
Lock, D. B. (2007), The Taiwan Stock Market Does Follow a Random Walk, Economics Bulletin, $7(3), 1-8$.

Łochowski, R. M. (2012), The Black-Scholes vs. the Merton jump-diffusion model applied to selected WIG20 companies in the year 2011, accepted to the monograph Zastosowanie Metod Ilościowych w Zarzadzaniu Ryzykiem $w$ Działalnośc Inwestycyjnej, PTE Katowice 2013.

Merton, R. C. (1976), Option pricing with discontinuous returns, Bell Journal of Financial Economics, $3(1-2), 145-166$

Neftci, N.S. (1998), An Introduction to the Mathematics of financial Derivative ( $2^{\text {nd }}$ ed.), Academic Press.

Pradhan, R. S., Balampaki, S.B. (2004), Fundamentals of stock returns in Nepal, SEBON Journal, 1, 8-24.

Pradhan, R. S., KC, S. (2010), Efficient Market Hypothesis and Behaviour of Share Prices: The Nepali Evidence, SEBON Journal, 4,104-117.

Wilmott, P. (1997), Derivatives: The Theory and Practice of Financial Engineering $\left(2^{\text {nd }}\right.$ ed.), John Wiley \& Sons Ltd.

Wilmott, P., Howison S. and Dewynne, J. (1997), The Mathematics of financial Derivatives: a Studen Introduction ( $2^{\text {nd }}$ ed.), Cambridge University Press.
Choakchai Eaimrittikrai

\section{ABSTRACT}

As businesses rely, in most countries, increasingly on the knowledge-based and value-added components of their offerings to secure suitable demand, the pressure on their internal infrastructur to maintain security has intensified. The range of potential adversaries continues to increase as commercial opportunities from cyber-attacks on their connectivity networks increases in both scope and scale. This paper considers the types of cyber-attacks that are being faced by organizations across East Asia and places these in the context of the political-economy of contemporary intellectual property rights. It is argued that multiplying risks threaten to overwhelm those organizations not prepared to take the issue seriously and to respond to those threats with appropriate rigor. Some implications for future practice are also derived from the analysis.

Keywords: Cyber attack, threat, political economy

\section{Introduction}

Since the introduction of internet technology and its various applications, the threats posed by and its malicious attackers have weighed heavily upon the brains of managers and executives. In a constant infiltrators and protectors of organizational networks have engaged in escalating forms of cyber-warfare. In some cases, this warfare is the result of simple theft or fraud, while in other cases national interests are alleged to have been at stake. This paper examines the different forms of cyberattack which have become apparent in recent years and then sets this in the context of the environment of intellectual property rights and possible piracy of them in the East Asian risks threaten to overwhelm those organizations not prepared to take the issue seriously and to respond to those threats with appropriate rigor.

2. Types of Cyberattack

There are three principal forms of cyberattack that need to be considered. The first of these is the type of cyb type of cyberive andivals are aimed, beyond simple malice, at extorting series of different rounds of conflict, both would-be East Aslan region. It is a pued that multiplying money from victims or tricking them into revealing sensitive details which can then be used to steal money or other resources from them. The secon type of threat is large-scale cyberattack, which is part of a state-level strike against the economic infrastructure of another country, either as part of open warfare or, more likely, as part of the campaigns of covert struggle that continues mostly away from public scrutiny. The third type of threa is cyberterrorism, which involves large-scale attacks against the online resources of individuals or organizations of a particular country or counties aiming to cause of a paricular cour

Just about every 'spam' email sent is an attempt to which are unsolicited and usually sent in bulk (Youn \& McLeod, 2007). Since they are unsolicited messages, they need to have an attractive sounding title to encourage recipients to open them and so have a chance to achieve their goals. This involves providing supposed infor go This tecive about reciving large and unexpected sums of money, the possibility of engaging in an intimate relationship or else through replication of the kind of emai

\subsection{Small-Scale Cyberthreat} commit a crime. 'Spam' means a kind of message title that is routinely received during daily or work 
life. The message itself will often try to engage the recipient in some form of communication, in the course of which s/he will be encouraged to reveal some personal details which can be used to connit some form of identily find. Spanging has become inceasingly prevalent - it has long since begun to outnumber the amount of genuine email - by 11 to 10 by 2007 (Clayton, 2007) - because the cost of sending bulk emails (using addresses harvesting automatically and without supervision) is so law and just one success is sufficient to justify a large number of spam efforts. Even so, email filter systems and the awareness of most email users have both improved to the extent that comparatively few spams now appear on screens before possibly few spans nossibly ent longer before they receive any attention. It is these reasons that, along with the incredible proliferation of mobile conmunication devices, that have persuaded spammers to attack the new medium of communication. These days, increasing attention is being placed on spam targeting mobile device users aimed primarily at inducing recipients to click on a site that contains malware that will connect to premium rate SMS services, which is the means by which spammers collect money. Messages to mobile devices now reach users within at most 15 mines of being senth minutes of being sent and, given the relationships between device and user, tonds to be slightly more rusted than email sent by conventional means (Ward, 2012).

Evidence suggests that competency in cyberattacks such as this and those methods discussed below has been concentrated in specific areas where high levels of technical skills are accompanied by few opportunities for meaningful and legal income generation from those skills, as occurs now in countries of the former Soviet Union (Glenny, 2012)

\subsection{Denial of Service (DoS) Attack}

A denial-of-service attack aims to make a website unusable by flooding it with such large numbers of requests for information and response that the system is overwhelmed. This is often in the form of a distributed denial-of-service (DDoS) attack, in which many third party computers are captured ('zombies') as a result of attack and organized into a coordinated attack on the target. An efficient DDoS can be mounted by a single user enlisting thousands of zombie machines on her behalf.

\subsection{Phishing and Identity Theft}

This kind of attack intends to find informatio about an individual which can be used to pose as the individual and thereby remove their money or other resources. The simplest form of this attack is to send a spam email claiming to be from a bank or other trusted institution and asking the recipient to type in bank account details in a fake recipient Those in be fake website. Those details are then stored and used in the rea website. More sophisticated attacks, which now increasingly feature mobile communication devices and social networking sites, involve telephone calls or other means of making personal to try to inject the degree of trust required to convince victims to yield their information to criminals.

\subsection{Keylogging and Eavesdropping}

This form of attack involves introducing a program to the victim's device that will record entere keystrokes and then analyse the records obtained so as to search for sequences that might represen credit card numbers or passwords. The sensitive information yielded can then be used in identity fraud.

People who have suffered from this kind of attack are by no means only the naive or poorly-educated: there has for example, recently been a series of successful attacks aimed at university faculty members, who have found their egos, flattered by supposed offers of free travel, accommodation an conference registrations owing to their importan academic contributions and in return for a modes upfront fee. The embarrassment that victims feet about their lack of perspicacity tends to abou the reck of perspicacity tends to mea that the repore dangers are not just to wallet an self-esteen but can lead to serious indebtedness, declare bankruptcy, have false admissions of guilt submitted to the police and so forth. To some extent, small businesses can be more vulnerable to these kinds of attacks, especially at a low level. It is quite common for a small business owner to pay invoices without fully checking their provenance in rushed and perhaps chaotic circumstances. It is also possible that those owners would rather not reveal the fact of their losses to the police becro no reveal helice because a deal of time and effort being required because of the involvement of the authorities. Countries which have less well-developed regulatory regimes and police forces of dubious reliability will be likely to suffer from less sophisticated fraud attacks.

\subsection{Cyberattacks}

Cyberattacks are, as explained above, more commonly associated with individuals or small groups of people seeking to make profit from attacking individuals or private sector corporations. Cyberattacks on public sector organisations have, mostly, been conducted on the basis of bravado ather than desire for profit. However, this situation has changed somewhat with the emergence of organized state-level attacks by one state on the economic and governmental interests of another. Currently, this subject is very difficult to investigate accurately because the legality of such actions is questionable but at the best a provocation to retaliation and at worst an act of war. Second, it remains difficult to prove openly who is responsible for what. This resembles the espionage activities of the Cold War, when a coup perpetrated by one side upon the other side represented such a propagide victon the victory that he victins would racher keep quiet the offence than use it to accuse the perpetrator. The hackers and those who oppose them, therefore, occupy a shadowy world in which their exploits are most unlikely ever to be brought to light. Indeed, the questionable legality of most if not all acts involved mean that those committing acts might find themselves sacrificed for the sake of satisfying public opinion.

The country most often accused of being involved in cyber warfare is China, both because of the high level of technical capacity within the country and because of the perception that the Chinese authorities have some intentions to dominate other countries. Cyberattacks of different sorts have been reported by the French, Belgian, German, Indian, Japanese, American governments and others. These Jave emails using social networking and cyberespionage by a group of hackers. Cyberespionage involves taking over a target computer or bypassing security precautions to make changes that would disable or destroy systems in the country (this section is informed by Krekel, 2009). This could be disastrous if it led, for example, to an electricity black-out in a hospital or mass transit system or the lowering of flood barriers. Attacks were in some cases attributable to specific political events, such as the attack on the French government facilities shortly fter on the French goventing after an illegitimate representative of a province of China.
Attacks have also been registered by groups of 'Hacktivists' - that is, people using hacking skills and competencies in the service of political campaigns - aimed at the government of Taiwan, which nitist pross to believe will day be reunited with the mainland. Of course, international politics has a significant role to play in these issues: attacks that receive publicity an official attention tend to be those which serve to provide a political benefit to one power or anothe or else as a means of obtaining or maintaining market position. For example, the American House of Representatives' Intelligence Committee, which is controlled by corporation-friendly Republicans, published a report arguing that the large Chinese telecommunications companies Huawei and ZTE che should be prohibited from enterin Arthur, 2012).

\subsection{Cyberterrorism}

Hackers and hacktivists have demonstrated method which might be used by cyberterrorist groups or individuals who wish ill on governments or people. Distributed Denial of Service (DDOS) attacks, for example, use viruses or malware to take control of large number of under-protected computers arou the world whi the w' army " that is ordered to make repeated requests fo information or access to a particular website. The sheer weight of traffic that can be involved can lead to servers being overwhelmed and websites going own for perhaps an extended period of time. It is not hard to imagine how attacks of this sort, perhap combined with cyber espionage and direct physical action, could lead to destruction on a significan scale. In an age in which terrorist outrages have been used to increase the power of governments with rect whe police to sectrity the police and of public spaces and the deploymen of drone technology at home and abroad (Coaffee, Wood \& Rogers, 2009), it is not surprising both that there have been calls for increasing anticyberterrorism threats (Jain, 2005) and that large amounts of resources have been deployed to try to achieve it.

This of course presents commercial opportunitie for individuals and organisations working with the software security industry. In Taiwan, for example, it has been estimated that the increasing need for security together with the 100-year anniversary of the creation of the ROC, which will mean an extra digit will be required to signify some dates 
on computer systems, not to mention the passing of the Personal Data Protection Act, will see continual rises in the size of the industry for the forthcoming years (Staff Writer, 2010).

In Korea, meanwhile, where the threat of cyber and direct action from North Korean agencies remains a troubling reality, people were shocked to find one of the companies most trusted for its ability to provide online safety had itself been used as a host in a cyberattack that involved the theft of personal details of 35 details of 35 among the most popular and trusted in the country. One result of the hacking attack - apparently using Chinese ISP numbers - is the launching of class action suits against those deemed to be culpable (Kim, 2011). In addition to these threats, the Korean state must also deal with the military threat of North Korea and the possibility of cyberattack weakening the defence system, for example in the case of antimissile defences (Song, 2011). There is no doubt that these are that these are genuine threats and require serious consideration.

3. Protection against Cyberattacks

The principal problem when organizing defences against potential or actual cyberattack is the need to avoid human error or betrayal, just as in earlier days the main problem with protecting banks was the possibility of individuals giving away secret he possibili protection software exists to protect systems but this is of little use if users are careless about protecting their password access codes or if they are casual about maintaining security protocols.

Most large-scale cyberattacks are intended to target Microsoft software. This is not because that software is any more vulnerable than that of other companies (although it does of course have numerous vulnerabilities which are constantly being tracked and solved by company representatives) but because it is overwhelmingly the most popular or at least most commonly used. Apple software is at least as vulnerable as Microsoft.

4. The International Political Economy of Intellectual Property Rights

Faked or pirated intellectual property represents a lucrative market opportunity for operators at a variety of scales. At the low end, a single individual with an ordinary PC could use this machine to produce a string of illicitly copied films or software discs. These can then be sold on the street or through a retail outlet in places where the police can be persuaded to turn a blind eye. This kind of Kuala Lumpu and However, this is not a phenomenon purely in action in developing countries: illegal Chinese migrant in the UK, for example, are able to earn income selling illicit DVDs of mostly pornographic film on the streets of British cities (Pai, 2008).

The concept of IPR is a comparatively modern one and it is generally applied in a discriminatory manner. During the period of rapid industrializatio of western countries (Chang, 2003), the concept of copyright was not in operation and corporations an individuals freely used IP from wherever they could find it if it looked like it would turn a profit for them. There is, therefore, a degree of hypocrisy in industrialized countries criticizing less develope countries for doing what they themselves did in order to become rich.

There is certainly a powerful thirst for what are called digital rights and which are linked with civil liberties more generally. This may be determine by the spread of the so-called Pirate Parties, which for their members in several countries of Europe, Austalia and Norh America. The Swedish Pipe, Australia and Noth Anerica. The Swedish Pirate Party was extablished in 2006, for example, while in 2011 15 members of the German Pirate Party were elected to the Berlin state legislature (Pidd 2011). Pirate Parties are particularly popular among the young and the technologically literate and have certain similarities with anarchist movements. In common with anarchism, they stress the importance of trusting people to make their own decisions and to be able to be responsible for dealing with sensitive information. In this sense they hav direct connection with the and the rejection of state sececy in goperation The Wikilects expor state secrecy in governance. The Whilcaks exposures have shown that a grea deal of what is done in the name of a country is done secretly or else illegal or disreputable act are committed to achieve state goals. Government agencies generally maintain that the normal, routine business of diplomacy cannot be conducted in the light of public scrutiny because of the exigencies of Realpolitik - that is, the need to resort to Machiavellian means to obtain required aims about which it is better for the people to know nothing. The anarchist of Pirate Party re such actions are too unpleasant or disreputable to be brought to the attention of the public, then they should not be taking place at all. Everything should be open and free for inspection. This approach poses a consich mechanisms, many of which are predicated on high levels of secrecy and confidentiality about actions taken. It is very difficult to reconcile these very different approaches.

Within electoral politics, Pirate Parties work to repeal legislation which they consider to be repressive and to maintain access to all forms of information and data that have been produced. From a commercial perspective, this leads to the dissonance between two different concepts of the business model. On the one hand, production of information leads to its distribution and sale, with any compromise of the sales process leading directly to reduced revenue. On the other hand are business models which accept that some part of information products will be distributed for free - perhaps even a great deal of the product - but revenue will be obtained through different methods. As discussed previously, website th it very difficult to recoup suffient reverue foun advertising based means to ren mo mounce a fully featured service, while firewall-

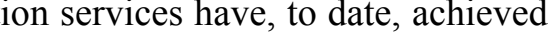
only very low levels of loyal customers.

5. Knowledge Management in the Era of Intellectual Piracy

Living in an age of both intellectual piracy and the increasing com orcial importance of information, it is necessary for corporations to take particular care of the information that is part of their competitive advantage. In some cases, corporations will try to keep every aspect of their operation secret and will require their staff to sign undertakings that keep hem bound to cofientiality. However, this is ultimately a self-defeating effort because working in such conditions is poor for morale and absolute secrecy is almost impossible to maintain, anyway, especially if those charged with keeping the secrets do not accept the importance of doing so. It is better to identify those issues which genuinely are important to the competitive advantage and communicate to staff privy to that knowledge of its worth and the need to keep things quiet. An alternative is to restrict knowledge to an absolute minimum of people and make a feature of the secrecy: this is the method adopted by KFC with its chicken recipes, for example, or Coca Cola and its components

What are the implications of living in a world in which it is necessary to maintain confidentiality? The first is that the need for confidentiality generally manifests itself at the personal, individual level. At its most basic level, this involves the use of passwords before logging on to computers or networks and the subsequent monitoring of online activities by the IT department. This is a process that can protect both employers and employees: in That can py the both Thailand, for exanple, extrencly repressive lèse majeste laws and their policing by many thousand of Ministry staff can be used to prosecute not jus those who make comments deemed offensive bu anyone else in a position of authority who did no remove the comments or other material with as great a degree of rapidity as the officials deem necessary. Hence, keeping a record of who has done what on the network might quite literally keep some people

Second, at a corporate or least workplace level, is necessary to insulate the organizational network from the remainder of the internet. This is a twoway process, in that there is some information which should not be transmitted outwards and anothe set of information that should not be transmitted inwards. IT departments, not to mention managers senerally, are wont to seize the power that flows generally, are wont to seize the power that flows from abusing their time at work by blocking services an websites which are more commonly associated wit entertainment than work (e.g. instant messaging, online game sites, Youtube and so forth). Several issues stem from this decision:

Is it possible that employees can use technological features to improve their creativity and productivity from below, using or perhaps subverting internet-based features to foster new forms of competitiveness?

Do people have a right to access the internet to maintain their connection with the outside world and indeed, their family members? In most workplaces, it has become custom and practice to accept that employees can use telephones (land lines or mobile phones) to keep in touch with family members an to manage issues with dependents such as children that might otherwise require them to stay away from work. If children customarily communicate via Facebook or instant messenger, should not their carers be able to access those services, at least at certain times of the working day? 
Does limiting the use of internet services actively harm the corporation concerned or, at least, hinder its ability to develop competitive advantage to its utmost? Depending on the type of business involved, there may be a definite advantage to be to be mined if it can be demonstrated that members of the organization are engaged with the business and its stakeholders, are knowledgeable and indeed possibly expert opinion-leaders. Anumber of companies have either permitted their employees to demonstrate this knowledge and engagement or, more commonly, tried to create situations in which such interest and engagement may be created and displayed.

\section{Conclusion}

This paper has aimed to explore some of the range of threats affecting organizations in East Asia via cyberattack. Assaults may originate from, simply, fraudsters and thieves or, in other cases, it has been alleged that state-level agencies and interests have been involved. It has been shown that the ambivalent attitude of a number of state agencies in victim countries towards intellectual property rights adds an extra level of complexity to the struggle to end end cyb ext heft and fraud ingeneral would help states to reduce isks for the organizations located within them.

7. References

Arthur, Charles, "China's Huawei and ZTE Pose National security Threat, Says US Committee, Guardian Guardian (October $8^{\text {th }}, 2012$ ), available at: http:// www.guardian.co.uk/technology/2012/oct/08/ china-huawei-zte-security-threat.

Chang, Ha-joon, Kicking away the Ladder: Development Strategy in Historical Perspective (London and New York, NY: 2003).

Clayton, Richard, "Email Traffic: A Quantitative Snapshot," Proceedings of the CEAS - Fourth Conference on Email and Anti-Spam (August, 2007), available at: http://ceas.cc/2007/papers/ paper-76.pdf.

Coaffee, Jan, David Murakami Wood and Peter Rogers, The Everyday Resilience of the City: How Cities Respond to Terrorism and Disaster (Basingstoke: Palgrave Macmillan, 2009).

Glenny, Misha, Dark Market: How Hackers Became the New Mafia, (London: Vintage, 2012).
Jain, Gaurav, "Cyber Terrorism: A Clear and Present Danger to Civilised Society? Information Systems Education Journal, Vol 3, No.44 (August $\left.12^{\text {th }}, 2005\right)$, available at: http:/ http://isedj.org/3/44 ISEDJ(44)Jain.pdf.

Kim, Hyung-eun, "ESTsoft Was 'Host' of Massive Cyber Caper," Korea Joongang Daily (Augus $\left.6^{\text {th }}, 2011\right)$, available at: http://koreajoongangdaily. joinsmsn,com/news/article/article. aspx?aid=2939860.

Krekel, Bryan, Capability of the People's Republic of China to Conduct Cyber Warfare and Computer Network Exploitation, US-China Economic and Security Review Commission (McLean, VA: Northrop Grumman Corporation, 2009), available at: http://www.dtic.mil/cgi-bin GetTRDoc? Location $=\mathrm{U} 2 \&$ doc $=$ GetTRDoc pdf\&AD=ADA509000.

Pai, Hsiao-hung, Chinese Whispers: The True Story behind Britain's Hidden Army of Labour (London: Penguin, 2008).

Pidd, Helen, "Pirate Party Leads New Breed out to Change European Politics," The Guardian (October 28 $8^{\text {th }}, 2011$ ), available at: http://www. guardian.co.uk/world/2011/oct/28/pirate-partyeuropean-politics.

Song, Sang-ho, "Seoul to Upgrade Guided Missile Software," The Korea Herald (November $4^{\text {th }}$ 2011), available at: http://nwww.koreaherald.com/ view.php?ud=20111114000722.

Staff Writer, with CAN, "Information Security Software Seen as Crucial for Taiwan," Taipei Times (June $28^{\text {th }}, 2010$ ), available at: $h t t p: / / w w w . t a i p e i t i m e s$. com/News/biz/archives/2010/06/28/2003476585.

Ward, Mark, "Cyber Thieves Profit via the Mobile i Your Pocket," BBC News Online (November 12 2012), available at: http://www.bbc.co.uk/news/ tchnology-20080397.

Youn, Seongwook and Dennis McLeod, "Efficien Spam Email Filtering Using Adaptive Ontology," Proceedings of the Fourth International Conference on Information Technology (April, 2007), pp.249-54.

The Usage of Non-Biodegradable Packaging Materials, Recycling Strategies and Impacts on the Environment: the Case of Bahrain

Arpita Dutta

\section{ABSTRACT}

The increased usage of non-biodegradable packaging materials is an integral part of our modern life and they are used in many daily activities. Generally, plastics are synthesized from non-renewable sources and are mostly not biodegradable, while waste plastics are the cause of many of the serious environmental problems the world faces today. This study investigated consumer behaviour and perceptions related to the increased use of plastic bags in transporting household goods from shops. Specifically, the study identified the status and effectiveness of the use of non-biodegradable packaging methods amongst retailing establishments (cold stores and super markets) in the Kingdom of Bahrain in terms of usage, recycling strategies adopted, disposal, the problems encountered and impact on the environment. A descriptive study research method was used in this study. The researcher also used five point Likert-like scales in the study. The respondents strongly agreed that there is high usage of plastic bags in the Kingdom of Bahrain. The reasons given for this included durability, cheaper prices, lighter than other alternatives and easy storage. The respondents moderately agreed that recycling strategies adopted by both the retail establishments and the consumers are in place in the Kingdom of Bahrain but indiscriminate use and disposal of these plastic carrier bags does pose a significant environmental threat to the country. Again, the study found that since most plastic waste is disposed of in landfill sites where, although not visible, bags are nevertheless coming to the surface as debris and are affecting marine life as well as being ingested by animals like camels. In addition, the conditions within landfills are causing the chemicals contained within the plastic to become more readily available to the environment and this is a particular concern in a small island like the Kingdom of Bahrain, where landfill management is not as closely monitored as in the developed countries. Plastic carrier bags were found to be favoured in transporting high-risk food products to avoid possible cross contamination. Consumers' perceptions and usage behaviours in connection with respective government's policies and implementation of recycling systems could be highly decisive in reducing the eco-impact of plastic and paper shopping bags.

Keywords: disposal to landfill, plastic bags, recycle, reduce, reuse, usage

1. Introduction

In recent years, as a result of changes in people's consumption patterns, a large amount of waste plastic has been added to municipal solid waste (MSW) facilities and has caused serious environmental concerns. Among other materials, a huge range of oil-based polymers is currently used in packaging applications. They are largely nonbiodegradabl pecte or reuse due to mixed levels of contamination and complex composites. Almost all consumer goods purchased in everyday life come with packaging, which fulfils at least one of the following functions: to provide protection from physical damage, contamination and deterioration;

to give sales appeal;

to ensure the product identity is easily recognizable;

to give information about the product;

to optimize distribution and storage costs and to provide consumer convenience and safety. 